\title{
FACULDADE DE DIREITO DA UNIVERSIDADE DE SÃO PAULO
}

\author{
VÍTOR MONTEIRO
}

Limites constitucionais à autonomia dos entes federados em matéria de contratos administrativos

São Paulo

2014 


\section{VÍTOR MONTEIRO}

Limites constitucionais à autonomia dos entes federados em matéria de contratos administrativos

Dissertação apresentada à Faculdade de Direito da Universidade de São Paulo, para obtenção do título de Mestre em Direito

Área de Concentração: Direito do Estado

Orientador: Prof. Dr. Fernando Dias Menezes de Almeida

\section{São Paulo}




\section{RESUMO}

MONTEIRO, Vítor. Limites constitucionais à autonomia dos entes federados em matéria de contratos administrativos. 2014. 169 p. Dissertação (Mestrado em Direito) - Faculdade de Direito, Universidade de São Paulo, São Paulo, 2014.

O trabalho explora os limites impostos pelo texto constitucional de 1988 à autonomia dos entes federados quanto à distribuição da competência legislativa em matéria de contratos administrativos. Para tanto, dividiu-se a pesquisa em seis partes. Destas, as duas primeiras servem para, em linhas gerais, assentar os aspectos introdutórios da pesquisa e delimitar as noções conceituais adotadas. Segue-se para o enfrentamento das três hipóteses de pesquisa, cada uma em capítulo próprio, vislumbradas a partir do texto constitucional como inicialmente aptas a ordenar a distribuição da competência legislativa entre os entes federados para a edição das normas de contratos administrativos. Na primeira, discute-se, com base no artigo 22, XXVII, da Constituição de 1988, se caberia à União Federal, autorizada pelo termo "contratação", estabelecer normas gerais sobre contratos administrativos, competindo aos Estados-membros, Distrito Federal e Municípios, suplementarem aquelas, para atenderem às suas peculiaridades. Outra, constante do artigo 22, I, da Constituição de 1988, admitiria à União Federal legislar integralmente sobre a matéria, com fundamento na sua competência para estabelecer normas em matéria de Direito civil, ramo no qual a categoria jurídica dos contratos tem assento tradicional. A última hipótese, por sua vez, decorrente do artigo 18, caput, da Constituição de 1988, não atribuiria a nenhum ente federado a competência específica para legislar sobre o tema dos contratos administrativos, relacionando esta matéria ao campo próprio da autonomia dos entes federados. A despeito dessa liberdade para legislar, pondera-se, no exame desta hipótese e pela perspectiva da distribuição de competências entre os entes federados, quanto à existência de outros limites constitucionais, aptos a restringir a autonomia dos entes federados no uso dos contratos administrativos. Ao final, retomam-se, em sede de conclusão, as hipóteses formuladas e as considerações apontadas sobre cada uma delas ao longo do trabalho, apontando-se aquela que se entende mais adequada à estrutura federativa do Estado brasileiro.

Palavra-chave: contratos administrativos - federalismo - autonomia - competência legislativa - limites 


\begin{abstract}
MONTEIRO, Vítor. Constitutional limits to the autonomy of federated entities in matter of government contracts. 2014. 169 p. Dissertação (Mestrado em Direito) - Faculdade de Direito, Universidade de São Paulo, São Paulo, 2014.
\end{abstract}

This thesis probes on the limits that the Brazilian Constitution of 1988 sets to the autonomy of federated entities in regards to the distribution of the legislative competence in matter of government contracts. The research was divided in six parts. The first two have the purpose of laying out an introduction of the study as well as the concepts employed. Afterwards, the three hypotheses are confronted, each in a paragraph of their own, perceived as from the constitutional text as initially able to ordain the distribution of legislative competence between the federated entities to regulate government contracts. On the first, it is argued, based on the article 22, XXVII, of the Federal Constitution of 1988, if it would behoove the Federal Union, authorized by the term "contracting", to establish general rules on government contracts, competing to the Member-States, Federal District and Municipalities to supplement those, in order to attend their peculiarities. Another understanding, found in the article 22, I, of the Federal Constitution of 1988, would allow the Federal Union to fully legislate on the matter, grounded on its competence to establish rules in Civil Law, branch in which the legal category of contracts have a traditional place. The last theory, on its turn, consequent to the article 18, caput, of the Federal Constitution of 1988, would not assign to any federated entity the specific competence to legislate on government contracts, relating this theme to the proper field of autonomy of federated entities. In spite of this freedom to legislate, it is considered, in the exam of this hypothesis and from the perspective of distribution of competence between federated entities, in regards of the existence of other constitutional limits, able to restrain the autonomy of federated entities in the use of government contracts. Finally, it is resumed, in terms of conclusion, the hypotheses formulated and the considerations that were put forth in each of them through the project, pointing out the one understood as the most adequate to the federative structure of the Brazilian State.

Key words: government contracts - federalism - autonomy - legislative competence - limits 


\section{INTRODUÇÃO}

\section{Objetivo da pesquisa}

O objetivo desta pesquisa é investigar a competência dos entes federados brasileiros para expedir normas de contratos administrativos, diante da organização políticoadministrativa do Estado brasileiro, prevista na Constituição de 1988.

A Constituição de 1988 consagrou, em seu artigo $1^{\circ}$, a índole descentralizada da forma federativa de organização do Estado, instituindo pelo seu artigo 18, entes "autônomos, nos termos desta Constituição". Contudo, essa mesma Carta traz uma conformação que evidência o predomínio da União Federal no federalismo brasileiro. ${ }^{1}$ Nesta pesquisa, procura-se investigar, por meio do instituto dos contratos administrativos, os limites dessa preponderância, para não deturpar a forma de Estado prevista e dotar os entes federados periféricos do Estado brasileiro - Estados-membros, Distrito Federal e Municípios - do papel constitucionalmente admitido para o exercício autônomo de suas atividades. ${ }^{2}$

Desse modo, far-se-á, ao longo deste trabalho, um exame das disposições constitucionais da Carta de 1988 relacionadas ao tema dos contratos administrativos para, a partir da perspectiva da distribuição das competências legislativas entre os entes federados ligadas a esta matéria, perquirir os limites e a abrangência destas restrições, com o objetivo de definir o campo de ação autônoma dos entes federados quanto a esta espécie de contratos.

Com isso, o objeto desta pesquisa será testar a percuciência da tese lançada por Fernando Dias MENEZES DE ALMEIDA (2008a e 2012) para a leitura do artigo 22, XXVII, da Constituição de 1988, cuja redação prescreve competir à União Federal legislar privativamente sobre

normas gerais de licitação e contratação, em todas as modalidades, para as administrações públicas diretas, autárquicas e fundacionais da União, Estados, Distrito Federal e Municípios, obedecido o disposto no art. 37, $\mathrm{XXI}$, e para as empresas públicas e sociedades de economia mista, nos termos do art. $173, \S 1^{\circ}$, III.

Neste dispositivo, em que a doutrina majoritária vislumbra a competência legislativa da União Federal em matéria de contratos administrativos, inclusive as normas regedoras de

\footnotetext{
${ }^{1}$ Para este diagnóstico, a partir do estudo da distribuição das competências legislativas entre os entes federados pela Constituição de 1988, corroborado em julgados do Supremo Tribunal Federal, cf. Denise Cristina VASQUES, 2007.

${ }^{2}$ Neste sentido, são as palavras de Fernanda Dias Menezes de ALMEIDA (2010, 75): “[d]e fato, realisticamente, a preponderância da União no federalismo contemporâneo é um dado com que se tem de aprender e conviver. O que é preciso impedir é uma hegemonia do poder federal que desnature o sistema”.
} 
seu objeto, Fernando Dias MENEZES DE ALMEIDA (2008a, 200) faz "uma ressalva de índole substancial", tendo em vista a "excepcionalidade em relação à competência para legislar sobre Direito administrativo" e o "contexto constitucional, de modo a assegurar, também neste capítulo do Direito administrativo, a máxima autonomia para os entes federativos". Tal observação é assim enunciada pelo autor:

sem pretender aqui prender-me a uma interpretação meramente literal do texto, mas contextualizando-a, sistematicamente, no regime federalista -, penso haver importante diferença decorrente do uso pela Constituição, do vocábulo "contratação", em lugar de "contrato".

Contratação é a ação de contratar. Contrato é o objeto dessa ação.

Sendo assim, estariam contidos na noção de contrato, mas não na de contratação, os aspectos estruturais dos contratos administrativos (ex.: tipos contratuais, cláusulas necessárias, regime jurídico próprio). Por outro lado, contratação diria respeito a normas de regência do ato de contratar (ex.: necessidade de previsão de recursos orçamentários, respeito ao resultado do procedimento licitatório, controles externos e internos pertinentes). ${ }^{3}$

Assim, o objetivo desta pesquisa será tanto o exame da aderência dessa proposição ao contexto constitucional de 1988, quanto a análise dos demais caminhos que se abrem para a competência legislativa em matéria de contratos administrativos, ao se assumir o caminho interpretativo acima proposto, qual seja, de que artigo 22, XXVII, da Constituição Federal não outorga à União Federal competência legislativa em matéria de contratos administrativos.

Diante da ideia de que a competência legislativa em matéria de contratos administrativos não estaria contida no artigo 22, XXVII, o propósito do trabalho avança para explorar, a partir da prática legislativa nessa matéria, outras possíveis competências legislativas dos entes federados brasileiros para editar normas no tema. As duas possibilidades que serão exploradas são: (i) aquela relacionada à matéria de Direito civil, privativa da União Federal, prevista no artigo 22, I, da Constituição de 1988, e (ii) aquela fundada na autonomia do artigo 18 que observa a existência de limites ao seu exercício "nos termos" da Constituição de 1988.

\section{Motivos da pesquisa}

São razões para o desenvolvimento desta pesquisa as contribuições da forma federativa do Estado adotada pela Constituição Federal de 1988 e dos contratos administrativos para o aprimoramento da Administração Pública brasileira e do modelo de Estado Democrático de Direito.

\footnotetext{
${ }^{3}$ Fernando Dias MENEZES DE ALMEIDA, 2008a, 200-201.
} 
Sob o aspecto do aprimoramento da Administração Pública brasileira, esta pesquisa é motivada pela tentativa de aproximar o Direito administrativo da complexa estrutura que a Administração assume no Estado brasileiro, em face da organização político-administrativa federativa, partilhada em $5.598^{4}$ entes com administrações próprias.

Com esta aproximação quer-se destacar a assimilação de instrumentos do Direito administrativo de modo particularizado e adaptado à realidade de cada unidade federada. Neste sentido, pela perspectiva exclusiva dos contratos administrativos, um dos diversos instrumentos de manifestação do agir da máquina estatal, ${ }^{5}$ investiga-se os limites para que cada ente federado adote fórmulas legislativas próprias para regular a matéria, de modo a melhor satisfazer as suas necessidades.

Acredita-se que com o apontamento dos limites constitucionais à autonomia dos entes federados em matéria de normas de contratos administrativos deseja-se não só fazer com que este instituto do Direito administrativo reflita a organização da Administração Pública brasileira, como também permitir que as práticas administrativas melhor se adaptem à sua relação com os cidadãos ${ }^{6}$ ou em benefício da sua própria organização. ${ }^{7}$

Ainda que este aspecto criativo do agir administrativo prescinda da forma federativa de Estado, acredita-se que o modelo federativo, ao dotar os seus entes das capacidades políticas, financeiras, organizativas e administrativas, decorrentes da autonomia, gera, em cada unidade federativa, um ambiente potencial de criação de novas técnicas de atuação da máquina estatal. ${ }^{8}$ Neste ponto, os contratos celebrados pelas Administrações Públicas colaboram, pelo seu aspecto negocial e seu caráter sensível às especificidades e particularizações, na formulação de novas respostas às necessidades sociais, como foram,

\footnotetext{
${ }^{4}$ Para esta soma, considerou-se a União Federal, 26 Estados-membros, o Distrito Federal e 5.570 Municípios sobre a quantidade de Municípios brasileiros. Cf. Site do Instituto Brasileiro de Geografia e Estatísticas. Disponível em: 〈http://7a12.ibge.gov.br/voce-sabia/curiosidades/municipios-novos〉. Acesso em: 30/10/2013.

${ }^{5}$ Em outra ocasião (MONTEIRO, 2012), teve-se, em pesquisa de curto fôlego, a possibilidade de investigar, sob o prisma do instituto do processo administrativo, essa relação entre Direito, Administração Pública e forma federativa do Estado, no arranjo da Constituição de 1988.

${ }^{6}$ São exemplos de práticas nesses sentidos a adoção, no Município de São Paulo, do Sistema de Bilhetagem Eletrônica com Cartão Inteligente, conhecido como BILHETE ÚNICO, regulamentado pelo Decreto do Município de São Paulo 46.893, de 06 de janeiro de 2006, e, no Estado de São Paulo, a criação das Centrais de Atendimento ao Cidadão, denominado POUPATEMPO, instituídas pela Lei Complementar do Estado de São Paulo 847, de 16 de Julho de 1998.

${ }^{7}$ Nesse sentido, pode-se citar o programa de bonificação por resultados para os servidores em exercício da Secretaria de Estado da Educação, para a melhora e aprimoramento da qualidade do ensino público, instituído pelo Estado de São Paulo, mediante a Lei Complementar do Estado de São Paulo 1.078, de 17 de dezembro de 2008.

${ }^{8}$ Nesse sentido, Fernando Dias MENEZES DE ALMEIDA (2008b, 233) manifesta-se: “[e]ssa grande preponderância jurídica e política da União ao mesmo tempo freia a possibilidade de desenvolvimento das unidades que reúnem reais condições de exercício da autonomia e perpetua a situação de dependência das demais".
} 
nesse sentido, as Parcerias Público-Privadas para a construção de hospitais ${ }^{9}$ e presídios $^{10}$. Diante disso, parece ter pertinência investigar, ainda que restritamente ao âmbito dos contratos administrativos, os limites jurídicos para que a ação criativa dos entes federados dêse dentro dos parâmetros admitidos pelo ordenamento e se constituam de respostas abrangidas pelo Direito.

Deste contexto de novas soluções, esta pesquisa acaba também por encontrar suas razões na temática da discricionariedade administrativa. Este assunto, seguindo o que se apontou para a defesa da autonomia das unidades federadas, também pode ser visto como um mecanismo propício ao desenvolvimento de alternativas de gestão da máquina pública, quando se considera não especificamente a figura do agente público executor do ato administrativo discricionário, mas a perspectiva da liberdade do ente federado.

Com isso, procura-se inserir esta pesquisa nas discussões em favor de uma maior liberdade na celebração dos ajustes pactuados pela Administração Pública. ${ }^{11}$ Discutindo a matéria sobre a perspectiva da autonomia dos entes federados no Estado brasileiro na atividade legislativa regedora dos contratos administrativos, motiva esta pesquisa não só a contribuição ao âmbito de liberdade das Administrações Públicas de cada esfera federativa, para discricionariamente, exercerem sua autonomia, como também o foco deste estudo para circunscrever os limites desse campo de atuação, foco claro da doutrina jurídica de Direito administrativo, mesmo que de modo restrito aos contratos administrativos por elas celebrados. $^{12}$

${ }^{9}$ Ver, nesse sentido, Hospital do Subúrbio, realizado pelo Estado da Bahia, mediante contrato de parceria público-privada. Disponível

<http://www.sefaz.ba.gov.br/administracao/ppp/Contrato_N30_2010_parte1.pdf>

em:

<http://www.sefaz.ba.gov.br/administracao/ppp/Contrato_N30_2010_parte2.pdf>. Acesso em: 28/10/2013.

${ }^{10}$ Conferir a respeito o Complexo Penal de Ribeirão das Neves, realizado pelo Estado de Minas Gerais, mediante contrato de parceria público-privada. Disponível em: <http://www.ppp.mg.gov.br/projetos-ppp/projetoscelebrados/complexo\%20penal/arquivos-para-download-1/Contrato\%20PPP\%20Complexo\%20

Penal\%20330639.54.1338.09.pdf>. Acesso em 28/10/2013.

${ }^{11}$ Tratando de um tema relacionado a esta pesquisa, as licitações públicas, com o enfoque crítico em favor de uma maior discricionariedade do agente público, cf. André ROSILHO, 2013. Prefaciando esta obra, Carlos Ari SUNDFELD, assim se posiciona quanto à questão da discricionariedade: "[n]o mundo jurídico brasileiro é grande a convicção de que a discricionariedade administrativa seria a causa de todo o mal das contratações públicas. Daí o prestígio da maximalista Lei 8.666/1993, que buscou limitar fortemente a discricionariedade. Daí também a preferência dos órgãos de controle pelas interpretações que reduzam sempre mais os espaços de opção administrativa." (ROSILHO, 2013, 08)

${ }^{12}$ Para ilustrar a temática da discricionariedade administrativa em matéria de contratos administrativos, cf. Diogo de Figueiredo MOREIRA NETO $(2009,14)$ na defesa de cláusulas discricionárias para os contratos administrativos, em substituição às cláusulas exorbitantes, tocando num ponto central da teoria administrativa que caracteriza os contratos administrativos pela presença de cláusulas desta natureza, derrogatórias do direito comum: "[e]sta preferência pela escolha da técnica flexível da discricionariedade, em lugar da técnica rígida da vinculação, não encontra qualquer impedimento na legislação brasileira, pois essa imposição da generalização de cláusulas inafastáveis nos contratos administrativos não repousa sobre qualquer assento constitucional, senão que é de previsão meramente legal, nada impedindo, portanto, que o legislador ordinário delegue ao 
Ainda no contexto de aprimoramento da Administração Pública e relacionado ao colocado acima, outro intuito desta pesquisa está no alerta daquilo que Floriano de Azevedo MARQUES NETO (2009a, 77-79) chama de "maldição do regime único", caracterizada pela "aplicação irrefletida do regime jurídico administrativo", ${ }^{13}$ de modo que se propõe, no âmbito dos contratos administrativos e tendo como pano de fundo a forma federativa do Estado brasileiro, um repensar desta prática de um único modelo de contrato administrativo aplicável a todos os entes federados. Ora, admitir um regime jurídico, sem uma criteriosa análise de sua compatibilidade às exigências constitucionais parece obstar, sem fundamento normativo, os vetores postos, em maior medida, pela estrutura federativa do Estado brasileiro, conquanto, como já se brevemente indicou, é próprio desta forma de Estado a autonomia de suas unidades federadas, e, em menor medida, da figura dos contratos, já que se trata de um instrumento apto para servir às especificações da vontade negocial. ${ }^{14}$ Desse modo, esta pesquisa também encontra fundamento na tentativa de apontar o conjunto dos limites postos à competência legislativa dos entes federados nas atividades criativas em matéria de contratos administrativos.

Dito isso, segue-se para as motivações da pesquisa relacionadas ao aprimoramento do Estado Democrático de Direito brasileiro. Observa-se que pela miríade de abordagens que a noção comporta, limitar-se-á a apontar a alguns aspectos da contribuição ao tema ${ }^{15}$, ensejadas pelo federalismo e pelos contratos administrativos no aperfeiçoamento do aspecto democrático do Estado brasileiro, sob a noção de que, para a existência desta técnica de

administrador público esta oportunidade de avaliar a legitimidade do emprego de qualquer delas, depois de examinadas as hipóteses, caso a caso."

13 "Tal unicidade é a origem de várias mazelas. Impede a modulação de regime em virtude da finalidade da ação administrativa. Obsta a maior eficiência da máquina pública. Tende a tornar todas as relações de que participa o Estado relações de autoridade, marcadas pelo poder extroverso, em detrimento dos direitos dos administrados." (MARQUES NETO, 2009a, 78)

${ }^{14}$ Quanto aos contratos administrativos, Floriano de Azevedo MARQUES NETO (2009a, 78) assim registra o desconforto: "[e]mbora possamos cogitar de uma enormidade de tipos distintos de contratos de que o poder público pode participar, nosso Direito Administrativo (aqui não só a doutrina, mas também a Lei) procura reduzir tudo a um único regime contratual. E, pior, inspirado num tipo de contrato: a empreitada para obras de engenharia, molde das disposições da Lei no 8.666/1993. Ou seja, esteja a Administração a contratar um singelo fornecimento de água mineral, encomendar um projeto de arquitetura, comprar um sofisticado equipamento feito sob encomenda, contratar a construção de uma usina hidrelétrica ou delegar um serviço público ou a prestação de um serviço social, deveria ela se submeter a um único modelo de contrato, observar regras de um regime jurídico monolítico."

${ }^{15}$ Ao se realizar a aproximação entre federalismo e contratos administrativos, notadamente sobre a perspectiva do Estado Democrático de Direito, não se perde de vista que os termos possuem cargas axiológicas muito distintas. Os debates sobre a federação no campo do Direito do Estado vão além e tem abrangência muito maior do que aqueles relacionados aos contratos administrativos que compõem um ponto de estudo no âmbito do Direito administrativo, já que este, por sua vez, é apenas um dos diversos subramos do Direito do Estado. Guardadas estas devidas distinções, quer-se vislumbrar, nesta aproximação, a contribuição dos temas - maior do federalismo e menor dos contratos administrativos - para o aprimoramento do Estado Democrático de Direito. 
governar pressupõe-se um ambiente de Estado de Direito. ${ }^{16}$ Com isso, acredita-se que o desenvolvimento de estudos que avancem pela perspectiva descentralizada de organização do poder estatal, possibilitada pelo modelo federativo de Estado, adensa, mediante a promoção do controle pela partilha do poder entre as diversas unidades federadas, a construção dos meios institucionais de oposição e participação que, conforme aponta Robert A. DAHL (1997), constituem os elementos caracterizados de Estados mais democratizados. ${ }^{17}$

Nesse sentido, acompanhando o binômio oposição-participação, formulado por Robert A. DAHL (1997), a organização federativa do Estado parece poder contribuir de modo favorável ao desenvolvimento de Estados democratizados, conquanto, pela perspectiva da oposição, separa o poder, mediante o recurso da limitação espacial para o seu exercício, ${ }^{18}$ e, consequentemente, cria um ambiente apto à contestação pública, em face da pluralidade de núcleos institucionais de exercício do poder político, ${ }^{19-20} \mathrm{e}$, pelo prisma da participação, permite a aproximação, pela estrutura federativa de Estado, ${ }^{21}$ do exercício do poder pela Administração Pública aos cidadãos, registrando-se que esta não é uma condição exclusiva deste modelo de organização do Estado.

${ }^{16}$ Esta é a lição de Manoel Gonçalves FERREIRA FILHO (2001). Segundo o autor, a democracia "não dispensa certas instituições jurídicas. Embora tais instituições não digam respeito diretamente à organização do Poder, são elas essenciais na disciplina de seu exercício. Pode-se dizer que são elas condições institucionais dos regimes" (FERREIRA FILHO, 2001, 37). Entre essas condições institucionais está o Estado de Direito, na medida em que a sua "ideia central [...] consiste em sujeitar o Poder, na sua origem, no seu procedimento, no seu alcance e orientação a regras fixas, imperativas, numa palavra, as regras de direito" (FERREIRA FILHO, 2001, 95).

17 Como já se teve a oportunidade de apontar em trabalho específico (MONTEIRO, 2013a) sobre a compatibilidade do modelo da poliarquia, formulada por Robert A. DALH (1997), com a estrutura constitucional do Estado brasileiro, erigida pela Constituição de 1988, não haveria, acompanhando o referido autor, Estados plenamente democráticos, tendo em vista que o termo democracia recebe as mais variadas conceituações teóricas que não acompanhariam a estruturação dos Estados reais. Com isso, o referido autor formulou o conceito tipo da poliarquia, definindo que os Estados reais serão mais democratizados quanto maior for o nível de assimilação do seu regime de governo a um ambiente político de participação e oposição, vislumbrado sobre sete dimensões: sequências históricas; ordem socioeconômica; nível de desenvolvimento socioeconômico; igualdade e desigualdade; pluralismo subcultural; crenças de ativistas políticos; e dominação de um poder estrangeiro.

18 “"[A] divisão territorial do Poder, ínsita à descentralização própria do Estado Federal, constitui aporte típico deste modelo de Estado à contenção do arbítrio". (ALMEIDA, 2011, 225)

${ }^{19}$ Fernando Dias MENEZES DE ALMEIDA, 2011a, 240-243. Note-se que o aventado pluralismo político também pode ser relacionado com o aspecto da participação do binômio participação-oposição. Contudo, preferiu-se acompanhar a abordagem de Fernando Dias MENEZES DE ALMEIDA (2011a) que examina o pluralismo dos núcleos institucionais sob a perspectiva da organização territorial federativa do Estado e, portanto, como um elemento de controle do poder, ligado ao aspecto oposição do mencionado binômio.

20 “'[É] preciso sempre lembrar que os Estados constituem no Brasil um dos poucos corpos intermediários que aliviam dos indivíduos o peso opressivo do Poder central, um dos raros contrapesos ao Poder imperial da capital. Já pressentiram os pais de nossa Federação e isso continua plenamente verdadeiro. [§] Vale, assim, lutar pela preservação da Federação como garantia da liberdade política de todos os brasileiros." (FERREIRA FILHO, $2011,187)$

21 “'L]ouve-se a descentralização federativa como meio de fortalecer o sistema democrático, pela aproximação entre governantes e governados na tomada, pelos primeiros, das decisões que afetam os segundos. De fato, se a um único centro de poder incumbe decidir, sem um contato mais direto com o ambiente e com os destinatários a que se devem aplicar as decisões, compromete-se a liberdade-participação tão cara à Democracia." (ALMEIDA, $2011,225)$ 
Todos estes aspectos podem ser vistos também, ainda que em modesta contribuição, pela ótica dos contratos administrativos. Como um dos diversos instrumentos de materialização do agir da Administração Pública, os contratos administrativos podem constituir-se como a manifestação dos aspectos da oposição e da participação dos entes federativos. Para tanto, basta considerar que, no aspecto oposição, é um instrumento que manifesta a ação espacialmente limitada e politicamente plural, pois relacionada ao agir administrativo de cada ente da federação, e, quanto ao ângulo da participação, é um meio de agir que decorre do consenso entre as partes, enquanto técnica de ação negociada, no qual a aproximação entre os seus sujeitos é um elemento essencial do instituto.

Por fim, ainda quanto ao aspecto democrático do Estado brasileiro, resta explorar um último aspecto a dar razão para esta pesquisa, no qual a estrutura federativa de Estado e o instrumento dos contratos administrativos parecem poder contribuir: o desenvolvimento de uma igualdade material, na relação entre os entes federados, mediante um raciocínio em favor de um federalismo de índole assimétrica. Chama a atenção para este ponto Fernanda Dias Menezes de ALMIEDA $(2011,226-227)$ ao mencionar a conclusão de Rui BARBOSA ${ }^{22}$ de que "a igualdade consiste em tratar igualmente os iguais e desigualmente os desiguais, na medida em que se desigualam" para, ao relacioná-la à típica característica do federalismo de permitir a "acomodação da diversidade na unidade", afirmar que "a simetria nem sempre será a melhor receita para a organização federativa". Com isso, a autora, asseverando as "vantagens de um federalismo assimétrico", observa

22 Percorrendo a de Rui Barbosa (disponível em: <http://www.casaruibarbosa.gov.br/rbonline/obrasCompletas.htm>, acesso em: 30/10/2013), encontrou-se a aventada lição da igualdade em parecer - Subvenções municipais a escola de corporações religiosas interpretação do art. 72, $\$ \S 6^{\circ}$ e $7^{\circ}$, da Constituição (Rui BARBOSA, 1965, 153-197) - destinado a examinar a relação entre Estado e Igreja no contexto da Constituição de 1891, quanto às contribuições financeiras realizadas pela República brasileira às instituições religiosas católicas, como contrapartida ao ensino gratuito por elas oferecido, e a alegada desigualdade deste ato enquanto forma de tratamento privilegiado a esta entidade religiosa em detrimento de outras, numa clara promoção da desigualdade. Pugnando em favor da igualdade na questionada conduta estatal, são estas as palavras do autor: "[d]iriam que a escolha de um estabelecimento católico já é, de per si só, um ato de óbvia desigualdade em prejuízo das outras religiões. Mas, se à mercê do governo está não olhar, no estabelecimento que elege, à religião, em que ele se filia; se, do mesmo modo como elegeu o católico, lhe era lícito eleger o protestante, e se, na eleição pela qual se decide, não considera a religião do estabelecimento, mas o seu mérito profissional, a sua valia como organização docente, a sua eficácia como instituição educativa, - que desigualmente aí vai senão a desigualdade essencial a toda a justiça, a desigualdade comum a todas as leis da natureza, a desigualdade inseparável da igualdade perante a lei, a desigualdade consistente em tratar desigualmente as coisas desiguais, a desigualdade cujo critério se exerce, graduando as preferências consoante a superioridade verificável dos preferidos aos preteridos? [\$] Não haveria aí desigualdade, senão no mesmo sentido em que é desigual toda a igualdade jurídica; visto como toda ela consiste em acolher o direito, e rejeitar a usurpação, em absorver a inocência, e condenar o crime, em premiar o merecimento, e desclassificar a incompetência, em distribuir a estima, a honra, a confiança aos mais capazes e aos mais úteis." (BARBOSA, 1965, 182) 
[i]sso posto, é de todo aconselhável que a Constituição Federal, ao estabelecer os fundamentos que embasarão a prática federativa, municie desde logo os entes periféricos com instrumental capaz de potencializar sua autonomia, $[. .$.$] tendo em vista as circunstâncias peculiares de cada um.$

De fato, ainda que se pudesse argumentar que deve haver uma coerência no modelo federal de Estado, no que respeita ao feitio e ao funcionamento das instituições públicas em todos os planos da Federação, o certo é que, no mais das vezes, a importação obrigatória do figurino federal pelos Estados, nas esferas acima assinaladas, se determinada sem maior plausividade, equivale a uma desfiguração de sua autonomia e a um falseamento do verdadeiro sentido da igualdade. $^{23}$

Nesse sentido, fundamentado nos alertas de Manoel Gonçalves FERREIRA FILHO $(1972)^{24}$, Dircêo Torrecillas RAMOS $(1998)^{25}$ e Fernando Dias MENEZES DE ALMEIDA $(2011 a)^{26}$, em favor da promoção de um pensamento que vislumbre o federalismo assimétrico, motiva esta pesquisa questionar em que medida o arranjo da Constituição de 1988 permite que os contratos administrativos sirvam, como instrumento potencializador da autonomia dos entes federados, à promoção dessa técnica de igualdade material enquanto concretização do federalismo assimétrico.

Em suma, elencadas as razões para empreender esta pesquisa, registra-se o desejo de, combatendo aquilo que Marçal JUSTEN FILHO (2012, 68 e 83) chamou de "Direito Administrativo do espetáculo", marcado pela "proliferação de institutos e interpretações descolados da realidade", para "impregnar a atividade administrativa com o espírito da Constituição, de modo a propiciar os valores a realização efetiva dos princípios e valores ali consagrados", perquirir os poderes e limites de cada ente federado para a edição de normas de contratos administrativos, em face do quanto dispõe a Constituição de 1988, de modo que se possa estabelecer, no âmbito da federação brasileira, os pontos de extravasamento a serem combatidos e de acanhamento a serem superados, no manejo dos contratos administrativos pelas Administrações Públicas dos entes federados.

\footnotetext{
${ }^{23}$ Fernanda Dias Menezes de ALMEIDA, 2011a, 227.

24 "Não é exagero dizer que o princípio da paridade dos Estados-membros sufoca a virtude do federalismo $-a$ unidade na diversidade -, estabelecendo a absurda e injusta identidade na diversidade. Esse absurdo é um dos males que afligem a Federação brasileira". (FERREIRA FILHO, 1972, 114)

${ }^{25}$ Nesta obra dedicada ao tema do federalismo assimétrico, Dircêo Torrecillas RAMOS (1998) conceitua o tema da "assimetria no Sistema Federal" como "uma situação onde as diversidades dentro de uma sociedade maior encontra expressão política através dos governos componentes. Estes possuem vários graus de autonomia e poder. A unidade componente teria sob esses aspectos uma única característica ou conjunto de características que distingue seu relacionamento para com o sistema como um todo, para com a autoridade federal e para com outro Estado" (RAMOS, 1998, 94). Além desse delineamento, o autor aborda o problema tanto por uma ótica de fato (RAMOS, 1998, 101-108), como de direito (RAMOS, 1998, 109-112), e traz posicionamento sobre a questão no panorama da Constituição de 1998 (RAMOS, 1998, 261-288).

26 “"F]az-se cada vez mais necessária a discussão sobre a proposta de que se passe a permitir um tratamento desigual dos entes da federação, conforme seu grau de desenvolvimento, tanto no tocante às suas competências, como no tocante à sua organização”. (MENEZES DE ALMEIDA, 2011a, 242-243)
} 


\section{Indagações e Hipóteses}

Considerando o objetivo desta pesquisa, qual seja, investigar, em face da estrutura federativa do Estado, a competência legislativa dos entes federados brasileiros para editar normas de contratos administrativos, formulou-se a seguinte indagação a orientar o desenvolvimento desta pesquisa: a Constituição de 1988 estabelece disposições relativas às competências legislativas dos entes federados em matéria de contratos administrativos, limitando o exercício autônomo desta competência pelas unidades federadas?

Como resposta a essa indagação, vislumbram-se três possíveis hipóteses:

Hipótese A: A competência legislativa em matéria de contratos administrativos está disposta no artigo 22, XXVII, da Constituição de 1988, relacionada ao termo "contratação" constante daquele dispositivo, atribuindo à União Federal o poder de estabelecer normas gerais, limitando a competência legislativa dos entes periféricos a complementar, em suas peculiaridades, tais normas.

Hipótese B: A competência legislativa em matéria de contratos administrativos está disposta no artigo 22, I, da Constituição de 1988, sob o tema da competência da União Federal para, privativamente, legislar sobre "Direito civil", tendo em vista ser este ramo do Direito, tradicionalmente, o responsável por regular os institutos da teoria geral do direito, como a categoria jurídica dos contratos, dos quais os contratos administrativos podem ser espécie, obstando o exercício da competência dos demais entes federados no tema.

Hipótese C: A competência legislativa em matéria de contratos administrativos está disposta no artigo 18, caput, da Constituição de 1988, remanescendo no âmbito da autonomia das unidades federadas por se tratar de um instrumento ligado ao agir administrativo, devendo os entes federados, na regulação do tema observar como limites os termos postos pelo texto constitucional.

Para testar estas hipóteses, investigar-se-ão os fundamentos sobre os quais se assentam cada uma delas à luz da perspectiva da autonomia ensejada pela forma de Estado brasileiro e da própria conformação do instituto dos contratos administrativos.

Assim, em primeiro lugar, investigar-se-á a Hipótese A por vislumbrá-la como a mais tradicional na compreensão da matéria, em seguida se testará a Hipótese B por trabalhar com um tema de competência legislativa privativa da União Federal, concluindo a análise com o exame da Hipótese $C$.

Por fim, registra-se que, no desenvolvimento de cada ponto específico desta pesquisa, além da indagação e das hipóteses genéricas aqui indicadas, que permeiam toda a elaboração 
do trabalho, também forma formuladas outras, particulares aos temas postos em debate com este trabalho, sempre que se entendeu pertinente para melhor testar as indagações e as hipóteses formuladas.

\section{Método e Metodologia}

A proposta de trabalho apresentado seguirá o método de abordagem jurídico-positiva para as questões nele examinadas. Esta orientação, seguindo as lições de Norberto BOBBIO (1995, 131-133):

(i) encara o Direito não como um valor, mas como um fato;

(ii) define o Direito pelo elemento da coação;

(iii) vislumbra, entre as fontes do Direito, a legislação como a mais relevante;

(iv) encara a norma jurídica como um comando imperativo;

(v) tem em vista que as normas não podem ser examinadas isoladamente, mas pelo seu conjunto;

(vi) requer coerência do ordenamento, pugnando pela impossibilidade de coexistência de normas antinômicas;

(vii) admite a completude do ordenamento, não havendo que se falar em lacunas no Direito;

(viii) tem em consideração a interpretação como um conceito amplo, capaz de compreender toda a atividade científica do jurista; e

(ix) questiona, mas admite, a teoria da obediência à lei.

Sob estas considerações, o estudo investigará, em perspectiva jurídico-positiva, a autonomia dos entes federados em matéria de normas de contratos administrativos, mediante o exame da distribuição das competências estabelecidas no texto constitucional.

Desse modo, o objeto principal dessa pesquisa será a Constituição de 1988, por ser o texto constitucional o documento normativo hábil para delimitar o âmbito da autonomia dos entes federados num Estado organizado sob a forma federativa.

Além deste, serão também manejados como objeto de pesquisa, para dar suporte ao teste das hipóteses e responder às indagações lançadas neste trabalho, os textos constitucionais do período republicano brasileiro, anteriores ao de 1988, as legislações infraconstitucionais que regulam a matéria dos contratos administrativos, expedidas no âmbito federal, estadual e municipal, já que a partir delas pode-se determinar a abrangência do exercício da autonomia dos entes federados na matéria, e documentos correlatos ao exercício da atividade normativa, como debates e exposições de motivos de textos normativos. 
Doutrina e jurisprudência servirão enquanto objetos desta pesquisa para balizar a interpretação de dispositivos normativos e orientar a conceituação teórica do sistema jurídico e seus elementos.

Apontam-se também dois recortes metodológicos relacionados ao empreendimento desta pesquisa.

O primeiro decorre da estrutura federativa. Diante da diversidade de unidades federadas de mesma natureza, existente no Estado brasileiro para Estados-membros e Municípios, selecionou-se, para a visualização normativa pretendida no trabalho das normas estaduais e municipais, aquelas editadas pelos Estado de São Paulo e Município de São Paulo, respectivamente, tendo em vista tanto o local elaboração deste trabalho estar, ou ter estado, sob o campo de incidência dessas normas, como o fato deste trabalho ser elaborado no âmbito de um curso de pós-graduação de uma Universidade pública do Estado de São Paulo, cujo campus tem sede na mesma municipalidade. Neste cenário, não foram abordadas normas expedidas pela unidade federada da natureza Distrito Federal. Entende-se não haver prejuízo, nesta exclusão, para o exame do quadro de competências e limites do federalismo brasileiro em matéria de normas de contratos administrativos, uma vez que as competências legislativas do Distrito Federal são, em face do artigo 32, § $1^{\circ}$, da Constituição de 1988, idênticas àquelas conferidas aos Estados-membros e Municípios.

O segundo limite metodológico estabelecido decorre da análise jurisprudencial restrita ao âmbito das decisões proferidas pelo Supremo Tribunal Federal. O fundamento desta restrição decorre da competência deste órgão para a guarda das decisões de índole federativa durante o período republicano brasileiro.

Por fim, registra que outros aspectos de método e metodologia, utilizados em pontos específicos do trabalho, serão esclarecidos quando de sua abordagem, observando que, em todas as situações, foram seguidas as linhas gerais apontadas neste tópico.

\section{Aspectos formais}

Para o cumprimento dos requisitos formais de apresentação deste trabalho, seguiu-se, em linhas gerais, as Diretrizes para apresentação de dissertações e teses da USP: documento eletrônico e impresso - Parte I $(A B N T)^{27}$.

Assim, a apresentação da bibliografia ao longo do texto seguirá o sistema autor-data.

\footnotetext{
${ }^{27}$ UNIVERSIDADE DE SÃO PAULO, 2009.
} 
Observa-se que, para conferir maior fluidez ao texto, preferiu-se grafar integralmente o nome do autor citado, quando sua menção se dá no corpo do texto, acompanhado da data de publicação da obra e da página a que se faz referência em parênteses.

Quando o trecho citado não está imediatamente após o nome do autor, registrou-se a referência em nota de rodapé, dispensando-se o uso de parênteses.

Apenas nas situações de transcrições de citações em nota de rodapé é que se utilizou exclusivamente do sobrenome do autor, da data e da página da obra reproduzida, com todas essas informações em parênteses.

Quanto aos realces realizados pelos autores nos trechos transcritos, não se negritou, sublinhou ou grafou em modo itálico nenhuma cópia de texto. Todas as reproduções de texto seguiram o modo como foram elaboradas pelos seus autores.

Ressalta-se que nas menções bibliográficas em que foram citados obras de mesma autoria, publicadas num mesmo ano, acresceu-se ao ano de publicação letras, para individualização das obras citadas.

Quanto aos aspectos ortográficos, foram adotadas as regras do Acordo Ortográfico da Língua Portuguesa, estabelecido pelo Decreto 6.583, de 29 de setembro de 2008. Desse modo, na transcrição de textos doutrinários, jurisprudências ou legislativos escritos sob outros acordos ortográficos, adequou-se a grafia das palavras reproduzidas aos padrões linguísticos estabelecidos pelo mencionado Decreto, como se o seu autor estivesse escrevendo sob as normas ortográficas atuais, sem, contudo, modificar o termo utilizado, ainda que seu significado tenha se perdido e não corresponda ao uso atual da palavra. Escaparam desta modificação tão somente os textos estrangeiros de origem portuguesa, para os quais se preferiu manter a grafia utilizadas pelos seus autores.

Registra-se que para se referir a Estados, entes federados de índole regional, adotou-se a expressão Estado-membro, para não haver confusão quando desta menção, com a noção de Estado.

Por fim, anota-se que, estruturalmente, o trabalho foi dividido em capítulos, sendo que esta introdução e a conclusão não integram o campo de desenvolvimento do texto. Os capítulos, por sua vez, foram divididos em tópicos e estes em subtópicos. 


\section{CONCLUSÃO}

Para concluir este trabalho, retoma-se o que se assentou a cada investigação específica quanto às hipóteses formuladas.

No Capítulo II, após enfrentar o tema da competência legislativa de contratos administrativos como matéria constante do artigo 22, XXVII, da Constituição de 1988, fez-se algumas ponderações quanto ao fundamento desta compreensão hoje tradicional entre os estudiosos do Direito administrativo, qual seja, a aproximação entre o termo constitucional "contratação" e a noção de "contratos administrativos".

Perquirindo este aspecto na origem, quanto à criação do dispositivo na Assembleia Nacional Constituinte de 1987-1988, não se chegou a nenhuma conclusão em favor desta aproximação. No âmbito da jurisprudência do Supremo Tribunal Federal, nenhum julgado sobre o artigo 22, XXVII, da Constituição de 1988, enfrentou a regulação, por este dispositivo, da distribuição da competência legislativa em matéria de contratos administrativos. Foi a doutrina jurídica quem formulou esta aproximação, aparentemente, ao examinar o termo "contratação", à luz das disposições do estatuto jurídico dos contratos administrativos, constantes do Decreto-lei 2.300/1986, atribuindo à Constituição de 1988 o poder de chancela da aptidão da União Federal para estabelecer, por meio deste diploma normativo, normas gerais em matéria de contratos administrativos, pacificando o debate quanto à natureza das normas jurídicas deste diploma, se de Direito administrativo ou Direito financeiro.

Diante dessas considerações, acredita-se que esta formulação, aproximando o termo "contratação" à noção de "contratos administrativos" é antes fruto de uma técnica interpretativa da doutrina, sem respaldo seguro no âmbito de sua produção legislativa e sem qualquer confirmação definitiva do Supremo Tribunal Federal, na interpretação do texto de 1988.

Assim, ainda que sobre o fundamento em que foi construída - a aproximação entre "contratação" e "contrato administrativo" - a Hipótese A seja plausível, entende-se tratar de uma aproximação que não satisfaz o arranjo federativo do Estado brasileiro.

Ao admitir interpretação extensiva, em capítulo constitucional, no qual, para a harmonização da distribuição dos poderes e para a segurança jurídica ${ }^{28}$ das práticas adotadas

\footnotetext{
${ }^{28}$ Esclarece-se que a segurança jurídica promovida por uma leitura estrita dos dispositivos constitucionais, decorre da maior clareza dos limites sob os quais são postos os espaços de exercício do poder das unidades federadas, compatibilizando a prática dos entes federados ao texto constitucional, diminuindo incertezas quanto a
} 
pelos entes federados, exige-se uma leitura estrita, subverte-se aquilo que se entendeu como o fundamento da autonomia das unidades federadas.

$\mathrm{Na}$ busca de uma interpretação da distribuição de competências legislativas em matéria de contratos administrativos, foram formuladas outras duas hipóteses para solucionar a questão: Hipótese $B$, na qual a competência legislativa em matéria de contratos administrativos estria disposta no artigo 22, I, da Constituição de 1988, sob o tema da competência da União Federal para legislar privativamente sobre "Direito civil"; e Hipótese $C$, na qual a competência legislativa em matéria de contratos administrativos não teria sido atribuída a nenhum ente federado em específico, remanescendo no âmbito da autonomia das unidades federadas, em face do disposto no artigo 18, caput, da Constituição de 1988.

No exame da Hipótese B, empreendida no Capítulo III, entendeu-se haver um problema de aderência conceitual entre o ramo do Direito civil e os elementos adotados para caracterizar os contratos administrativos.

Ao conceituar contrato administrativo como o ajuste criador de situação jurídica individual, com potencial incidência de um regime jurídico de Direito público, regulado por normas de Direito administrativo de caráter heterônomo no âmbito dos contratos, impositivas de poderes autoexecutórios em favor da Administração Pública, afastou-se as normas de contratos administrativos da regência de Direito civil.

Esta afirmação não significa que as normas de Direito civil não incidam sobre os ajustes contratuais de caráter administrativo. Acredita-se que, em muitos casos, melhor seria se assim o fosse, com a incidência das disposições de contratos administrativos restrita aos aspectos de essencialidade pela presença da Administração Pública na avença ou em razão de alguma peculiaridade do objeto contratual.

Contudo, não se encontrou nas normas de Direito civil pela própria caracterização vislumbrada para a estruturação desse ramo do Direito a aptidão para tratar com normas típicas dos contratos administrativos, já que, embora repositório de elementos estruturantes da teoria geral do Direito do instituto dos contratos, as disposições de Direito civil são destinadas para regular as relações jurídicas particulares, marcadas sob a perspectiva de igualdade e autonomia entre as partes.

Neste cenário, são as disposições de Direito administrativo aquelas responsáveis por estabelecer o, ainda que potencial, regime jurídico de prerrogativas, derrogatório e exorbitante das normas de Direito civil.

constitucionalidade das ações empreendidas pelas Administrações Públicas das unidades federadas com outros sujeitos de direito. 
Deste modo, a aventada Hipótese $B$, ainda que não completamente afastada pela possibilidade das normas de Direito civil incidirem sobre os ajustes contratuais de natureza administrativa, no quanto forem admitidas ou não afastadas pelas normas de Direito administrativo, são insuficientes para atribuir à União Federal a competência legislativa privativa sobre a matéria dos contratos administrativos.

Com isso, avançou para o Capítulo IV, no exame da alternativa lançada com a Hipótese $C$, na qual a competência legislativa em matéria de contratos administrativos não foi atribuída a nenhum ente federado específico, remanescendo no âmbito de competência de cada unidade federada, pela sua relação com o agir administrativo.

$\mathrm{Na}$ análise dessa hipótese, pode-se observar não só que a matéria foi objeto de constante regulação em normas pelas unidades federadas estudadas, em aparente exercício legislativo autônomo, mas também, numa análise das normas de contratos administrativos mais recentes, uma prática legislativa em que a matéria é tratada pelas unidades periféricas com certa independência com relação à regulação federal.

Nesse sentido, ainda que não seja um aspecto pacífico, a perspectiva de análise da competência legislativa adotada pela Hipótese $C$ não parece ser estranha à realidade das normas de contrato administrativo no Direito brasileiro.

Assentado esse aspecto, registrou-se ainda com relação à Hipótese $C$ que cogitar de uma competência legislativa autônoma na matéria de contratos administrativos, não significa liberdade plena no uso dos contratos administrativos pelas unidades federadas.

Como registra o artigo 18, caput, da Constituição de 1988, o exercício da autonomia dos entes federados se dá "nos termos desta Constituição". Neste cenário, registraram-se alguns apontamentos em sede de distribuição de competências entre os entes federados, aptas a impor limites ao uso autônomo dos contratos administrativos pelas unidades federadas.

Nesta oportunidade, foram apontadas competências constitucionalmente estabelecidas e relativas a algumas matérias que, sem pretensão exaustiva, entendeu-se guardar uma íntima relação com a regulação normativa adotada pelos entes federados para as suas normas de contratos administrativos.

Dito isso, do enfretamento das hipóteses formuladas, espera-se ter atendido aos objetivos desta pesquisa, especialmente por demonstrar que, muita embora pacificamente aceita, a competência legislativa na matéria de contratos administrativos pode seguir, diante da atual conformação constitucional, por outras linhas interpretativas que não aquela tradicionalmente aceita da competência da União Federal da matéria, constante no artigo 22, XXVII. 
Opina-se sobre o que se desenvolveu nesta pesquisa, acreditando que a perspectiva mais condizente para privilegiar a estrutura federativa do Estado brasileiro é a adoção da Hipótese $C$, por admitir não só à União Federal, mas também que Estados-membros, Distrito Federal e Municípios legislem, com autonomia, em matéria de contratos administrativos, observados os limites impostos pelo texto constitucional.

Por fim, deseja-se que, com este trabalho, se tenha trazido diferentes perspectivas sobre o tratamento constitucional da competência legislativa em matéria de contratos administrativos, especialmente a partir da realidade normativa e doutrinária. 


\section{BIBLIOGRAFIA}

ALMEIDA, Fernanda Dias Menezes de. "A federação a serviço da Democracia e do Estado de Direito". In MENEZES DE ALMEIDA, Fernando Dias; AMARAL JÚNIOR, José Levi Mello do; LEAL, Roger Stiefelmann; HORBACH, Carlos Bastide (coord.). Direito Constitucional, Estado de Direito e Democracia: Homenagem ao Prof. Manoel Gonçalves Ferreira Filho. São Paulo, Quartier Latin, 2011, pp. 219-228.

2010.

Competências na Constituição de 1988, $5^{\text {a }}$ ed. São Paulo, Atlas,

AMARAL JUNIOR, José Levi Mello do. Medida provisória e sua conversão em lei. São Paulo, RT, 2004.

"Medida provisória na jurisprudência do Supremo Tribunal Federal: um balanço de 1988 a 2008", in MENDES, Gilmar Ferreira; BLANCO, Paulo Gustavo Gonet; VALE, André Rufino do (org.). A jurisprudência do STF nos 20 anos da Constituição. São Paulo, Saraiva, 2010, p. 170-181.

ARAÚJO, Edmir Netto de. Contrato Administrativo. São Paulo, RT, 1987.

ASSEMBLEIA NACIONAL CONSTITUINTE. Volume 244 - Projeto de Constituição Comissão de Sistematização, Substitutivo do Relator (Segundo). Brasília, Senado Federal, 1987a.

"Comissão de Sistematização - Reunião Extraordinária em 24/09/1987

a Reunião de 05/11/1987", in Diário da Assembléia Nacional Constituinte (Suplemento C), 1987b. Disponível em: <http://www.senado.gov.br/publicacoes/anais/constituinte/sistema.pdf $>$. Acesso em: 23/07/2013.

"Regimento Interno da Assembleia Nacional Constituinte - Resolução no. 2, de 25 de março de 1987", in Diário da Assembleia Nacional Constituinte (Ano I, no. 33), 1987c. Disponível em: <http://www2.camara.leg.br/atividadelegislativa/legislacao/Constituicoes_Brasileiras/constituicao-cidada/publicacoes/regimentointerno-da-assembleia-nacional/resolucao-2-1987>. Acesso em: 23/07/2013.

Volume 236 - Projeto de Constituição - Emendas oferecidas em plenário ao substitutivo do Relator - Volume I (Emendas 20792 a 24427). Brasília, Senado Federal, 1987d. Disponível em: <http://www.camara.gov.br/internet/constituicao20anos/DocumentosAvulsos/vol-236.pdf>. Acesso em: 23/07/2013.

. Volume 237 - Projeto de Constituição - Emendas oferecidas em plenário ao substitutivo do Relator - Volume II (Emendas 24428 a 27036). Brasília, Senado Federal, 1987e. Disponível em: <http://www.camara.gov.br/internet/constituicao20anos/DocumentosAvulsos/vol-237.pdf>. Acesso em: 23/07/2013. 
Volume 238 - Projeto de Constituição - Emendas oferecidas em plenário ao substitutivo do Relator - Volume III (Emendas 27037 a 31127). Brasília, Senado Federal, 1987f. Disponível em: <http://www.camara.gov.br/internet/constituicao20anos/DocumentosAvulsos/vol-238.pdf >. Acesso em: 23/07/2013.

. Volume 239 - Projeto de Constituição - Emendas oferecidas em plenário ao substitutivo do Relator - Volume IV (Emendas 31128 a 35111). Brasília, Senado Federal, 1987g. Disponível em: <http://www.camara.gov.br/internet/constituicao20anos/DocumentosAvulsos/vol-239.pdf>. Acesso em: 23/07/2013.

. Volume 251 - Projeto de Constituição (A) da Comissão de Sistematização. Brasília, Senado Federal, 1987h. Disponível em: <http://www.camara.gov.br/internet/constituicao20anos/DocumentosAvulsos/vol-251.pdf>. Acesso em: 23/07/2013.

Volume 235 - Projeto de Constituição - Primeiro Substitutivo do Relator da Comissão de Sistematização. Brasília, Senado Federal, 1987i. Disponível em: <http://www.camara.gov.br/internet/constituicao20anos/DocumentosAvulsos/vol-235.pdf>. Acesso em: 30/07/2013.

- “Comissão da Organização do Estado $-6^{a}$ Reunião Ordinária de 28/05/1987”, in Diário da Assembléia Nacional Constituinte (Suplemento). Brasília, Senado Federal, 1987j. Disponível em: <http://www.senado.gov.br/publicacoes/anais/constituinte/ ComESub.pdf $>$. Acesso em: 05/10/2013.

. “Comissão da Organização do Estado - $10^{\mathrm{a}}$ Reunião Ordinária de 12/06/1987", in Diário da Assembléia Nacional Constituinte (Suplemento). Brasília, Senado Federal, 1987k. Disponível em: <http://www.senado.gov.br/publicacoes/anais/constituinte/ ComESub.pdf>. Acesso em: 05/10/2013.

"Resolução no. 3, de 06 de janeiro de 1988 - Altera o Regimento Interno da Assembleia Nacional Constituinte", in Diário da Assembleia Nacional Constituinte (Ano II, no. 163), 1988a. Disponível em: $<$ http://www2.camara.leg.br/atividadelegislativa/legislacao/Constituicoes_Brasileiras/constituicao-cidada/publicacoes/regimentointerno-da-assembleia-nacional/resolucao-3-1987>. Acesso em: 23/07/2013.

. Volume 256 - Índice, por dispositivo, das emendas oferecidas em plenário. Brasília, Senado Federal, 1988b. Disponível em: <http://www.camara.gov.br/internet/constituicao20anos/DocumentosAvulsos/vol-256.pdf>. Acesso em: 23/07/2013.

. Volume 271 - Projeto de Constituição (A) - Quadro Comparativo Título III. Brasília, Senado Federal, 1988c. Disponível em: <http://www.camara.gov.br/internet/constituicao20anos/DocumentosAvulsos/vol-271.pdf>. Acesso em: 23/07/2013. 
Volume 298 - Quadro comparativo entre o texto aprovado em $1^{\circ}$ turno, o texto remunerado e revisado, e a redação para $02^{\circ}$ turno, organizado pelo Relator, Constituinte BERNARDO CABRAL. Brasília, Senado Federal, 1988d. Disponível em: <http://www.camara.gov.br/internet/constituicao20anos/DocumentosAvulsos/vol298.pdf>. Acesso em: 30/10/2013.

Volume 299 - Suplemento I - Projeto de Constituição - redação para o segundo turno de discussão e votação. Brasília, Senado Federal, 1988e. Disponível em: <http://www.camara.gov.br/internet/constituicao20anos/DocumentosAvulsos/vol-299sup01.pdf>. Acesso em: 30/10/2013.

Volume 299 - Projeto de Constituição (B) - 2o Turno. Brasília, Senado Federal, 1988f. Disponível em: <http://www.camara.gov.br/internet/constituicao20anos/DocumentosAvulsos/vol-299.pdf>. Acesso em: 30/10/2013.

Volume 300 - Projeto de Constituição (B) - 20 Turno - ERRATA. Brasília, Senado $\quad$ Federal, 1988g. Disponível em: <http://www.camara.gov.br/internet/constituicao20anos/DocumentosAvulsos/vol-300.pdf>. Acesso em: 30 de outubro de 2013.

Volume 303 - Projeto de Constituição (B) - Parecer do Relator sobre as Emendas oferecidas em Plenário. Brasília, Senado Federal, 1988h. Disponível em: <http://www.camara.gov.br/internet/constituicao20anos/DocumentosAvulsos/vol-303.pdf >. Acesso em: 30/11/2013.

. Volume 309 - Projeto de Constituição (B) - Título III - Emendas e Destaques Organizados por Dispositivos. Brasília, Senado Federal, 1988i. Disponível em: <http://www.camara.gov.br/internet/constituicao20anos/DocumentosAvulsos/vol-309.pdf>. Acesso em: 30/11/2013.

Volume 314 - Projeto de Constituição (C) - Redação Final. Brasília, Senado Federal, 1988j. Disponível em: <http://www.camara.gov.br/internet/constituicao20anos/DocumentosAvulsos/vol-314.pdf>. Acesso em: 30/11/2013.

. Volume 316 - Projeto de Constituição (D) - Redação Final. Brasília, Senado Federal, 1988k. Disponível em: <http://www.camara.gov.br/internet/constituicao20anos/DocumentosAvulsos/vol-316.pdf>. Acesso em: 30/11/2013.

ARAGÃO, Alexandre Santos de. "A concepção pós-positivista do princípio da legalidade”, in Revista de Direito Administrativo, volume 236. Rio de Janeiro, Renovar, 2004, pp. 51-64.

BARBOSA, Rui. Obras completas de Rui Barbosa - Trabalhos Jurídicos, vol. XLIII 1916, t. II, pref. org. e rev. por José Câmara. Rio de Janeiro, Ministério da Educação e Cultura, $1965 . \quad$ Disponível em: <http://www.casaruibarbosa.gov.br/rbonline/obrasCompletas.htm>. Acesso em: 30/10/2013. 
Obras completas de Rui Barbosa - A Constituição de 1891, vol. XVII - 1890, t. I, pref. e rev. por Pedro Calmon José Câmara. Rio de Janeiro, Ministério da $\begin{array}{lllll}\text { Educação } & \text { e } & \text { Saúde, } & \text { Disponível } & \text { em: }\end{array}$ <http://www.casaruibarbosa.gov.br/rbonline/obrasCompletas.htm>. Acesso em: 05/11/2013.

BARROSO, Luís Roberto. “A constitucionalização do direito e suas repercussões no âmbito administrativo". In: ARAGÃO, Alexandre Santos de; MARQUES NETO, Floriano de Azevedo (coord.). Direito administrativo e seus novos paradigmas. Belo Horizonte, Fórum, 2012, pp. 31-63.

BOBBIO, Norberto. O positivismo jurídico: lições de filosofia do direito, tradução Márcio Pugliesi, Edson Bini e Carlos E. Rodrigues. São Paulo, Ícone, 1995.

BORGES, Alice Gonzalez. Normas gerais no estatuto de licitações e contratos administrativos. São Paulo, RT, 1994.

BRUSCO, Dilsson Emílio, e RIBEIRO, Ernani Valter. O processo histórico da elaboração do texto constitucional, vol. I. Brasília, Câmara dos Deputados - Coordenação de Publicações, 1993a. Disponível em: <http://www.senado.gov.br/publicacoes/anais/asp/CT_ObrasProcesso.asp>. Acesso em: 23/07/2013.

O processo histórico da elaboração do texto constitucional, vol. II. Brasília, Câmara dos Deputados - Coordenação de Publicações, 1993b. Disponível em: <http://www.senado.gov.br/publicacoes/anais/asp/CT_ObrasProcesso.asp>. Acesso em: 23/07/2013.

BUZAID, Alfredo. O estado federal brasileiro. Brasília, Ministério da Justiça, 1971.

CAVALCANTI, João Barbalho Uchoa. Constituição Federal Brazileira: commentarios. Rio de Janeiro, Litho-Typografia, 1902.

CAVALCANTI, Themístocles Brandão. "O nosso Conselho de Estado", in Revista de Direito Administrativo, número 24. Rio de Janeiro, FGV, 1951, pp. 01-10.

CASSESE, Sabino. Las bases del derecho administrativo, tradução Luis Ortega. Madrid, Instituto Nacional de Administración Pública, 1994.

CENTRO DE ESTUDOS DE DIREITO RODOVIÁRIO - CEDRO. Estudos sobre a Lei Paulista 10.395/70. São Paulo, CEDRO, 1971.

CRETELLA JÚNIOR, José. Dos contratos administrativos. Rio de Janeiro, Forense, 1997.

DI PIETRO, Maria Sylvia Zanella. Direito administrativo, 23ª ed. São Paulo, Atlas, 2010a.

"Transformações na organização administrativa. Diretrizes, relevância, e amplitude do anteprojeto". In MODESTO, Paulo (coord.). Nova organização administrativa brasileira, $2^{\mathrm{a}}$ ed. Belo Horizonte, Fórum, 2010b, pp. 21-33. 
Parcerias na administração pública: concessão, permissão, franquia, terceirização, parceria público-privada e outras formas. São Paulo, Atlas, 2009. . "Inovações no direito administrativo brasileiro", in Revista Interesse Público, número 30. Porto Alegre, Nota Dez, 2005, pp. 39-55.

EISENMANN, Charles. Cours de Droit Administratif, tomo II. Paris, Librairie Générale de Droit et de Jurisprudence, 1983.

. "O Direito Administrativo e o Princípio da Legalidade", tradução por Ruth Barbosa Goulart, in Revista de Direito Administrativo, volume 56. Rio de Janeiro, Renovar, 1959, pp. 47-70.

ESTORNINHO, Maria João. A fuga para o direito privado, contributo para o estudo da actividade de direito privado da Administração Pública. Coimbra, Almedina, 2009.

HORTA, Raul Machado. Direito constitucional, $5^{\text {a }}$ ed., atualizado por Juliana Campos Horta. Belo Horizonte, Del Rey, 2010.

FERRAZ, Anna Cândida da Cunha. "União, estado e município na nova constituição: enfoque jurídico-formal", in Nova Constituição Paulista: Perspectivas. São Paulo: Cepam/Fundap, 1989.

FERRAZ JÚNIOR, Tercio Sampaio. Introdução ao estudo do direito, técnica, decisão, dominação, $5^{\text {a }}$ ed. São Paulo, Atlas, 2007.

FERREIRA FILHO, Manoel Gonçalves. Aspectos do Direito Constitucional Contemporâneo, $3^{\text {a }}$ ed. São Paulo, Saraiva, 2011.

A democracia no limiar do século XXI. São Paulo, Saraiva, 2001.

Paulo, Saraiva, 2000 .

Comentários à Constituição Brasileira de 1988, volume 1, $3^{\circ}$ ed. São

. Comentários à Constituição Brasileira, $4^{\mathrm{a}}$ ed. São Paulo, Saraiva,

1983.

A democracia possível. Saraiva, São Paulo, 1972.

GONZALES, Douglas Camarinha. Competência legislativa dos entes federados; conflitos e interpretação constitucional. Dissertação (Mestrado em Direito). Faculdade de Direito da Universidade de São Paulo. São Paulo, 2011.

JUSTEN FILHO, Marçal. "O Direito Administrativo de espetáculo". In: ARAGÃO, Alexandre Santos de; MARQUES NETO, Floriano de Azevedo (coord.). Direito administrativo e seus novos paradigmas. Belo Horizonte, Fórum, 2012, pp. 65-85.

Rio de Janeiro, Aide, 1994.

Comentários à Lei de Licitações e Contratos Administrativos, $3^{\mathrm{a}} \mathrm{ed}$. 
LOPES, José Reinaldo de Lima. O Oráculo de Delfos - o Conselho de Estado no BrasilImpério. São Paulo, Saraiva, 2010.

MARQUES NETO, Floriano de Azevedo. "Do contrato administrativo para a administração contratual", in Revista dos Advogados, ano XXIX, número 107. São Paulo, AASP, 2009a, pp. 74-82.

Bens públicos: função social e exploração econômica - o regime jurídico das utilidades públicas. Belo Horizonte, Fórum, 2009b.

"O uso de bens públicos estaduais por concessionárias de energia elétrica", in Revista de Direito Administrativo, volume 236. Rio de Janeiro, Renovar, 2004, pp. 01-31.

Regulação estatal e interesses públicos. São Paulo, Malheiros, 2002.

MIRANDA, Pontes de. Comentários à Constituição de 1946, Tomo I, $3^{a}$ ed. Rio de Janeiro, Borsoi, 1960a.

Borsoi, 1960b.

. Comentários à Constituição de 1946, Tomo II, $3^{\mathrm{a}}$ ed. Rio de Janeiro,

MEDAUAR, Odete. Direito administrativo moderno, 14ª ed. São Paulo, RT, 2010.

"Constituição de 1988: catalizadora da evolução do Direito

Administrativo?", in Revista do Advogado, ano XXVIII, número 99. São Paulo, Associação dos Advogados de São Paulo, 2008, pp. 100-107.

O direito administrativo em evolução, $2^{a}$ ed. São Paulo, RT, 2003.

MEIRELLES, Hely Lopes. Licitação e contrato administrativo, $7^{a}$ ed. São Paulo, RT, 1987.

MENEZES DE ALMEIDA, Fernando Dias. Formação da Teoria do Direito Administrativo no Brasil. Tese (Concurso Professor Titular). Faculdade de Direito da Universidade de São Paulo. São Paulo, 2013.

Contrato administrativo. São Paulo, Quartier Latin, 2012.

"Dez Ideias sobre a Liberdade, extraídas da Obra de Manoel Gonçalves Ferreira Filho". In MENEZES DE ALMEIDA, Fernando Dias; AMARAL JÚNIOR, José Levi Mello do; LEAL, Roger Stiefelmann; HORBACH, Carlos Bastide (coord.). Direito Constitucional, Estado de Direito e Democracia: Homenagem ao Prof. Manoel Gonçalves Ferreira Filho. São Paulo, Quartier Latin, 2011a, pp. 229-250.

- “As parcerias público-privadas e sua aplicação pelo Estado de São Paulo”. In SUNDFELD, Carlos Ari (coord.). Parcerias público-privadas. São Paulo, Malheiros, 2011b, pp. 563-581. 
. "Contratos administrativos". In: JABUR, Gilberto Haddad, PEREIRA JÚNIOR, Antonio Jorge (coord.). Direito dos Contratos II. São Paulo, Quartier Latin, 2008a, pp. 193-216.

"Conflitos entre entes federativos: atuação do Supremo Tribunal Federal no regime da Constituição de 1988". In: MORAES, Alexandre de (coord.). Os 20 anos da Constituição da República Federativa do Brasil. São Paulo, Atlas, 2008b, pp. 217 234.

MODESTO, Paulo (coord.). Nova organização administrativa brasileira, $2^{\mathrm{a}}$ ed. Belo Horizonte, Fórum, 2010.

MONTEIRO, Vera. "Concessão e prévia autorização legislativa: STF e TJSP têm algo a dizer", in MENEZES DE ALMEIDA, Fernando Dias; MARQUES NETO, Floriano de Azevedo; MIGUEL, Luiz Felipe Hadlich; SCHITATO, Vitor Rhein (coord.). Direito público em evolução: estudos em homenagem à Professora Odete Medauar. Belo Horizonte, Fórum, 2013, pp. 457-465.

- "Legislação de parceria público-privada no Brasil - competência legislativa em matéria de concessão". In: SUNDFELD, Carlos Ari (coord.). Parcerias público-privadas. São Paulo, Malheiros, 2011, pp. 82-101.

Concessão. São Paulo, Malheiros, 2010.

MONTEIRO, Vítor. "A poliarquia de Robert A. Dahl na estrutura constitucional brasileira", in Revista da AJURIS, ano XL, número 129. Porto Alegre, AJURIS, 2013a, pp. 279-296.

. "Interesse público e consensualidade administrativa: o caso dos contratos de parcerias", in Fórum de Contratação e Gestão Pública, ano 12, número 134. Belo Horizonte, Fórum, 2013b, pp. 66-80.

- "Desafio à codificação do processo administrativo no ordenamento brasileiro: a forma federativa de Estado", in Revista Digital de Direito Público, vol. 1, n. 1, 2012, pp. 94-115. Disponível em: <www.direitorp.usp.br/periodicos>. Acesso em: 30/10/2013.

MORAND-DEVILlER, Jacqueline. Cours de Droit Administratif, $9^{\text {a }}$ ed. Paris, Montchrestien, 2005.

MOREIRA NETO, Diogo de Figueiredo. "O futuro das cláusulas exorbitantes nos contratos administrativos", in Fórum de Contratação e Gestão Pública, ano 8, número 93. Belo Horizonte, Fórum, 2009, pp. 07-18.

. "Competência concorrente limitada: o problema da conceituação das normas gerais”, in Revista de Informação Legislativa, ano 25, número 100. Brasília, Senado Federal, 1988, pp. 127-162.

MUKAI, Toshio. Estatutos jurídicos de licitações e contratos administrativos, $2^{\mathrm{a}}$ ed. São Paulo, Saraiva, 1990. 
OLIVEIRA, Gustavo Justino de. Contrato de Gestão. São Paulo, RT, 2008.

OLIVEIRA, Mauro Márcio. Fontes de informações sobre a Assembléia Nacional Constituinte de 1987: quais são, onde busca-las e como usá-las. Brasília, Senado Federal Subsecretaria de Edições Técnicas, 1993. Disponível em: $<$ http://www.senado.gov.br/publicacoes/anais/constituinte/fontes.pdf >. Acesso em: 23/07/2013.

OLIVEIRA, Regis Fernandes de. Curso de direito financeiro, $3^{\text {a }}$ ed. São Paulo, RT, 2010.

PALMA, Juliana Bonacorsi de. Atuação Administrativa Consensual: estudos dos acordos substitutivos no processo administrativo sancionador. Dissertação (Metrado em Direito). Faculdade de Direito da Universidade de São Paulo. São Paulo, 2010.

RAMOS, Dircêo Torrecillas. O Federalismo Assimétrico. São Paulo, Plêiade, 1998.

RAMOS, Elival da Silva, e ALMEIDA, Fernanda Dias Menezes de. "Auto-organização dos Estados Federados”, in Revista de Direito Público, ano XIX, número 79. São Paulo, 1986.

SILVA, José Afonso da. Comentário contextual à Constituição, $7^{a}$ ed. São Paulo, Malheiros, 2010.

Malheiros, 2005.

Curso de Direito Constitucional Positivo, 24 ed. São Paulo,

SOBRINHO, Manoel de Oliveira Franco. Contratos Administrativos. São Paulo, Saraiva, 1981.

Da competência administrativa: origens constitucionais e fundamentos jurídicos. São Paulo, Resenha Universitária, 1977.

SCHULER, Anelise Domingues. Finalidade da organização federal: entre descentralização, centralização e ceticismo. Tese (Doutorado em Direito). Faculdade de Direito da Universidade de São Paulo. São Paulo, no prelo.

SUNDFELD, Carlos Ari. "Uma lei de normas gerais para a organização administrativa brasileira: o regime jurídico comum das entidades estatais de direito privado e as empresas estatais". In: MODESTO, Paulo (coord.). Nova organização administrativa brasileira, $2^{\mathrm{a}}$ ed. Belo Horizonte, Fórum, 2010, pp. 57-67.

RIVERO, Jean. Direito administrativo, tradução Rogério Ehrhardt Soares. Coimbra, Almedina, 1981.

ROSILHO, André. Licitação no Brasil. São Paulo, Malheiros, 2013.

TEPEDINO, Gustavo. Temas de Direito Civil, Tomo III. Rio de Janeiro, Renovar, 2009.

UNIVERSIDADE DE SÃO PAULO. Diretrizes para apresentação de dissertações e teses da USP: documento eletrônico e impresso - Parte I (ABNT). São Paulo, Sistema Integrado de Bibliotecas da USP, 2009. 
VASQUES, Denise Cristina. Competências legislativas concorrentes: prática legislativa da União e dos Estados-membros e jurisprudência do Supremo Tribunal Federal. Dissertação (Mestrado em Direito). Faculdade de Direito da Universidade de São Paulo. São Paulo, 2007.

VENOSA, Sílvio de Salvo. Direito civil: parte geral, 5a ed. São Paulo, Atlas, 2005. 